\title{
CAPÍTULO 18 OBTENÇÃO DE DADOS SOCIOECONÔMICOS PARA A GESTÃO TERRITORIAL
}

DOI: http://dx.doi.org/10.18616/pgt18

Tales Garcia Antunes

Micael Etelvino Fernandes Desengrini

Caroline Bernardo Silva 


\section{INTRODUÇÃO}

A leitura do território é indispensável para poder melhorar a qualidade de vida da população, bem como as bases cadastrais de uma gestão territorial. As necessidades são ilimitadas quando se fala em gestão, mas os recursos disponíveis, muitas vezes, são escassos.

Para que sejam tomadas medidas capazes de alavancar o nível de desenvolvimento dos diferentes territórios do mundo, é necessária a obtenção de dados, estatísticas e informações que permitam identificar quais são os principais problemas que as populações e os lugares vivem. Por esse motivo, é de fundamental importância, além das análises de conjuntura, a geração de dados que possam atuar como indicadores socioeconômicos, aqueles que apontam as características básicas do desenvolvimento das sociedades (JANUZZI, 2009).

\section{TIPOS DE DADOS SOCIOECONÔMICOS}

Dentre os principais indicadores socioeconômicos, podemos destacar: o PIB, a renda per capita, o IDH, o coeficiente de Gini, o nível de desemprego e a oferta de serviços públicos à população. A seguir, confira uma explicação geral sobre cada um desses conceitos.

a. Produto Interno Bruto (PIB): é um importante conceito referente à riqueza produzida pelas atividades econômicas de um determinado país. Seu valor corresponde a tudo o que foi produzido e devidamente consumido, seja esse consumo direto ou indireto. Também tem referência utilizada em diversas mensurações, por exemplo: um país qualquer investe $6 \%$ do seu PIB em educação, ou seja, ele utiliza em verbas públicas um valor equivalente a $6 \%$ de todas as riquezas que são produzidas em seu país. Se o PIB aumenta, a verba da educação, portanto, também aumenta. 
b. Renda per capita: é a distribuição das riquezas produzidas no país pela sua população. No entanto, ao contrário do que muitas pessoas pensam, ele não é calculado a partir do PIB, mas sim do PNB (Produto Nacional Bruto), que, resumidamente, é o valor do PIB subtraído pelo capital que deixa o país e somado ao capital que entra no país.

c. Índice de Desenvolvimento Humano (IDH): é um conceito elaborado pela ONU na década de 1990 com vistas à obtenção de mais dados sobre o desenvolvimento social para além de informações puramente econômicas, levando em conta a qualidade de vida da população como um todo.

d. Taxa de desemprego: é um dos principais problemas que podem ser enfrentados por um país, pois representa tanto uma ausência de renda por boa parte da população quanto a redução do mercado consumidor. Não por acaso, as grandes crises econômicas sempre afetaram a população por meio da elevação das taxas de desemprego. Por esse motivo, os órgãos oficiais sempre estão atentos a esse importante indicador socioeconômico. No caso do Brasil, quem cuida disso é o Instituto Brasileiro de Geografia e Estatística (IBGE) e, embora esse dado tenha permanecido baixo nos últimos tempos, ainda é muito monitorado, pois, caso comece a elevar-se, medidas econômicas emergenciais precisarão ser tomadas.

e. Oferta de serviços públicos: a qualidade de vida da população, em muitos casos, está também associada à oferta de serviços pelo Estado, dentre os quais podemos destacar o saneamento básico (coleta de lixo e rede de água e esgoto), a iluminação pública e outras infraestruturas, tais como o asfalto e a sinalização de ruas e estradas. 


\section{PESQUISA, FONTES DE DADOS E INDICADORES NO BRASIL}

Os indicadores sociais e econômicos formatados de acordo com pesquisas e fontes de dados subsidiam governos, empresas e sociedade sobre o retrato dessa sociedade em seus diversos segmentos e áreas de análise no tocante à questão social, situação econômica da região estudada, aspectos estruturais administrativos, legais, educacionais, força produtiva, cultura e tantos outros cenários para o planejamento estatal.

a. IBGE: Instituto Brasileiro de Geografia e Estatística, instituto de pesquisas de trabalha com pesquisa e tratamento de dados socioeconômicos e demográficos, para uma determinada aplicação no planejamento governamental, em sua análise estatística, além de outras agências de pesquisas não governamentais que fazem parte do cenário de institutos pesquisadores.

b. PNAD: pesquisa nacional por amostra de domicílio, tem por propósito a atualização dos dados do censo demográfico em informação nacionais, estaduais e regiões metropolitanas, não considerando aqui a municipalidade representativa no papel extensivo de um censo nacional.

c. MUNIC: uma outra pesquisa que o IBGE realiza é o MUNIC, Pesquisa de Informações Básica Municipais, que trata de um levantamento sobre a estrutura administrativa, nível de participação e controle social, escopo legislativo, instrumentos de planejamento e orçamento municipal, aplicação de recursos público em educação, justiça, saúde, lazer, saneamento, coleta de lixo e limpeza urbana, como também, informações sobre comércio, indústria e tantas outras necessárias para retrato da localidade.

d. MINISTÉRIO DO TRABALHO: entre os órgãos que registram suas atividades, planejamentos, programas, projetos, pode-se 
relatar o Ministério do Trabalho, que realiza o levantamento de dados sobre emprego e desemprego nacional, características dos empregados, movimentação de mão de obra, tanto do regime celetista ou estatutário, através dos sistemas Cadastro Geral de Empregados e Desempregados (CAGED) e Relação Anual de Informações Sociais (RAIS), excluídos aqui aqueles que não possuem carteira de trabalho assinada, autônomos, profissionais liberais e informais.

\section{TIPOS DE MAPAS SOCIOECONÔMICOS E SUAS APLICAÇÕES}

Os mapas são veículos de transmissão de conhecimento (NOGUEIRA, 2009). Assim sendo, podemos verificar que a cartografia é uma ferramenta de gestão territorial para estudos e levantamentos de fatores sociais e econômicos. Com o crescimento dos países, também aumentam as desigualdades e as diferenças sociais. Logo, é importante o estudo e mapeamento das questões que englobam a sociedade. No Brasil, a Constituição Federal ${ }^{1}$ atual determina que a competência cartográfica é de responsabilidade da União:

Art. 21. Compete à União: (Exclusiva só ela faz). IBGE. XV - organizar e manter os serviços oficiais de estatística, geografia, geologia e cartografia de âmbito nacional.

Assim, no âmbito nacional essa competência é do IBGE (Instituto Brasileiro de Geografia e Estatística), no qual desenvolve suas pesquisas em três grandes áreas indispensáveis ao território, que são: população, economia e geociências.

1 BRASIL. Constituição da República Federativa do Brasil. Congresso Nacional, Brasília, 1988. Disponível em: <www.planalto.gov.br>. Acesso em: 16 out. 2016. 
No mapeamento constante do território, a obrigação legal imposta pela Constituição Federal faz com que a União mantenha a coleta de dados e pesquisa de maneira constante. O mapeamento dos dados socioeconômicos é uma tendência mundial, adotada por inúmeros países signatários da cartografia mundial. No caso da União, atribuição do IBGE.

Logo, a centralização e levantamento dos dados cartográficos pela União não é de hoje, pois a Constituição Federal de $1967^{2}$ já previa essa atribuição federal. O cotejo da discussão é muito interessante, uma vez que a política de cartografia e levantamento de dados possui caráter essencial no desenvolvimento e questionamento social. O cadastro tem seu tripé fundamental baseado na medição técnica, legislação e retorno econômico (LOCH; ERBA, 2007).

O IBGE atualmente dispõe de uma ferramenta chamada Web Cart Beta ${ }^{3}$, na qual o usuário pode, com os dados contidos no canal Cidades@, montar um mapa com as informações oficiais do órgão.

Figura 1 - Mapa população residente alfabetizada no estado de Santa Catarina

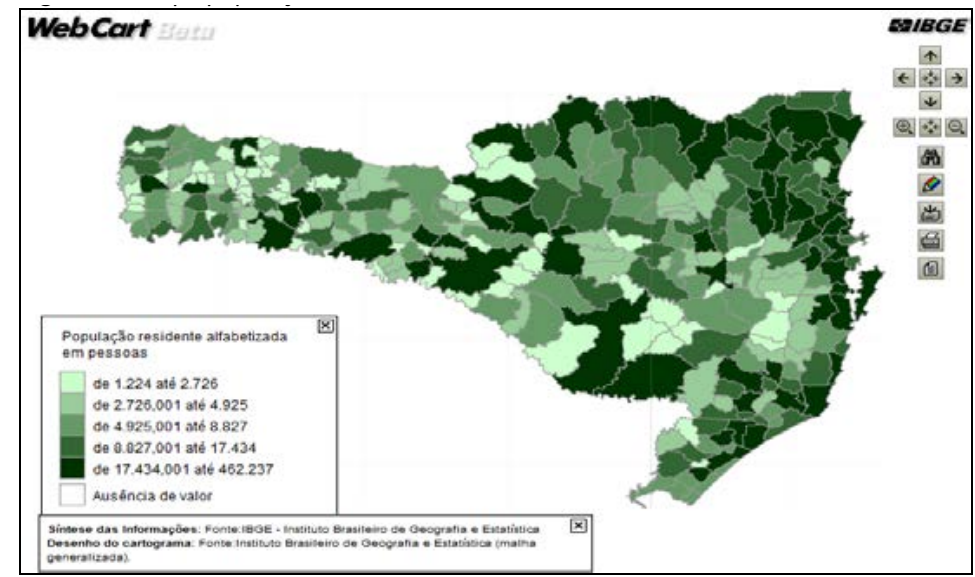

Fonte: IBGE. Ano de 2016.

2 BRASIL. Constituição da República Federativa do Brasil. Congresso Nacional, Brasília, 1967

3 IBGE. Site Institucional. Disponível em: <http://www.ibge.gov.br/webcart/>. Acesso em: 14 jul. 2016. 
O IBGE também dispões de outros mapas socioeconômicos predominantes, por exemplo, o de pobreza e desigualdade, no território de Santa Catarina. Outros, como o PIB, RENDA, IDH, ALFABETIZAÇÃO e SAÚDE, são exemplos de mapas socioeconômicos.

Na visão de Loch (2004), atualizar o cadastro é inserir e dar publicidade dos reais problemas que o gestor municipal enfrenta, como questões de mobilidade, patrimônio público, ambiental e de recursos do solo. 0 cadastro é um instrumento de política fiscal e urbana e foi ampliado com a edição do Decreto Lei n. 6.666, de 2008, no qual instituiu a Infraestrutura Nacional de Dados Espaciais (INDE), no âmbito do Poder Executivo Federal, e dá outras providências, com a seguinte redação:

Art. 10 Fica instituída, no âmbito do Poder Executivo federal, a Infraestrutura Nacional de Dados Espaciais - INDE, com o objetivo de:

I - promover o adequado ordenamento na geração, no armazenamento, no acesso, no compartilhamento, na disseminação e no uso dos dados geoespaciais de origem federal, estadual, distrital e municipal, em proveito do desenvolvimento do País;

II - promover a utilização, na produção dos dados geoespaciais pelos órgãos públicos das esferas federal, estadual, distrital e municipal, dos padrões e normas homologados pela Comissão Nacional de Cartografia - CONCAR; e III - evitar a duplicidade de ações e o desperdício de recursos na obtenção de dados geoespaciais pelos órgãos da administração pública, por meio da divulgação dos metadados relativos a esses dados disponíveis nas entidades e nos órgãos públicos das esferas federal, estadual, distrital e municipal.

Atualmente, o IBGE, além da previsão Constitucional de cartografia e mapeamento, possui responsabilidade junto ao Portal Brasileiro de Dados Geoespaciais (SIG Brasil), bem como pela gestão do Diretório Brasileiro de 
Dados Geoespaciais (DBDG), inclusive com designação de apresentação das propostas dos recursos necessários para a implantação e manutenção da INDE.

Contudo, os estados e municípios da Federação podem organizar dentro de suas competências territoriais atribuídas pela Constituição Federal de 1988, e ampliada nas constituições estaduais e leis municipais. Os setores cartográficos e de dados socioeconômicos para administração do seu território. Isso permite cooperação de informações para o planejamento.

A competência estadual para planejamento de seu território é plena, devendo ser exercida nos limites impostos pela União. Os estados da Federação concentram geralmente ao setor de planejamento o mapeamento das questões socioeconômicas dos Estados.

Nota-se que também pode haver uma integração de informações, entre as ferramentas do IBGE e os dados municipais, como demostrado no mapa de pobreza e desigualdade, elaborado pelo IBGE, mas com dados dos municípios de Santa Catarina. As partes em verde claro destacam os municípios com maior número de pobreza e desigualdade social no estado.

Figura 2 - Mapa de Índice de Pobreza e Desigualdade em SC

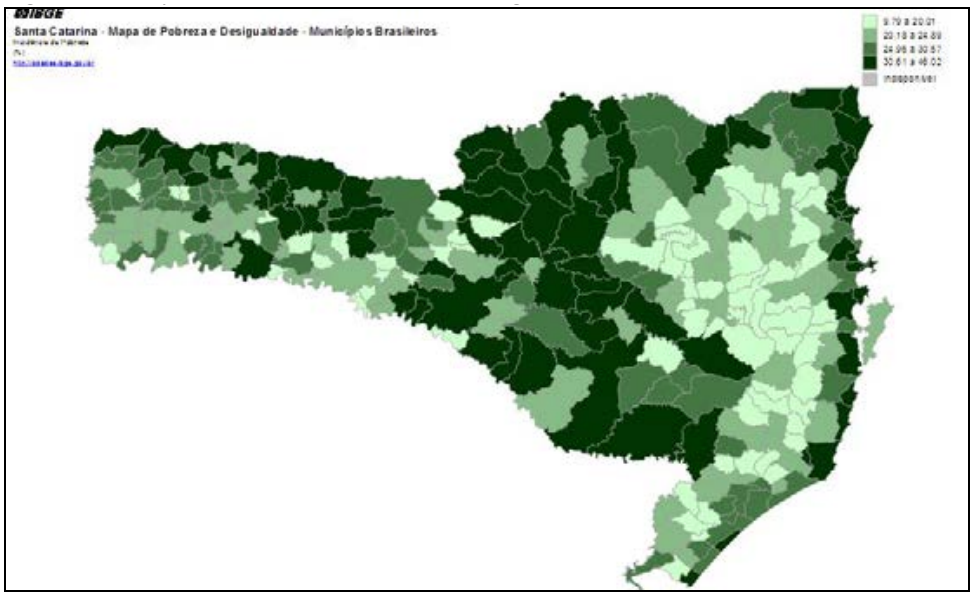

Fonte: IBGE, 2016. 
Muitas vezes, esses dados são fornecidos pelo IBGE, por meio de cooperação entre os órgãos ou pelos órgãos do próprio estado. Como exemplo, pode-se citar o estado de Santa Catarina, pois sua organização das estatísticas e cartografia está ligada à Secretaria de Planejamento Estadual. O mapa de desigualdade é uma construção do IBGE, por meio de transmissão de informações, sendo que, na ferramenta Web Cart Beta, qualquer usuário pode, com os dados contidos no canal Cidades@,montar um mapa com as informações oficiais do órgão. O produto ainda está em fase beta.

\section{APLICABILIDADE PRÁTICA DOS MAPAS E OS TIPOS E MAPAS SOCIOECONÔMICOS}

A pesquisa e o desenvolvimento de mapas socioeconômicos têm uma aplicabilidade prática, que é suporte e ferramenta de gestão, não só para os gestores da União, estados e municípios, autarquias, fundações, mas para a sociedade como um todo e maneira ampla de debate crítico e de reflexão.

Temos vários tipos de representação de mapas com dados socioeconômicos: Pode-se dizer ainda que em nível: nacional, estadual, municipal e internacional.

\section{EXEMPLOS DE MAPA SOCIOECONÔMICO NA GESTÃO MUNICIPAL}

A cartografia municipal pode ser desenvolvida nos limites do município e nas suas áreas de interferência de interesse local, art. 30, I, da Constituição Federal, como ferramenta de otimização de políticas públicas. Assim, o mapeamento municipal urbano ou rural é importantíssimo na gestão e leitura da cidade, inclusive como ferramenta para a implantação e revisão do plano diretor. 
A leitura e planejamento do território por meio de cartografia está se tornando uma tendência a nível nacional, tendo em vista que a União está centralizando cada vez mais atribuições públicas aos municípios.

Contudo, cabe destacar a relação do município de São Paulo e seus estudos com a cartografia no âmbito do território municipal, desenvolvidos pela Secretaria Municipal de Desenvolvimento Urbano.

Figura 3 - Sistema Geo de São Paulo

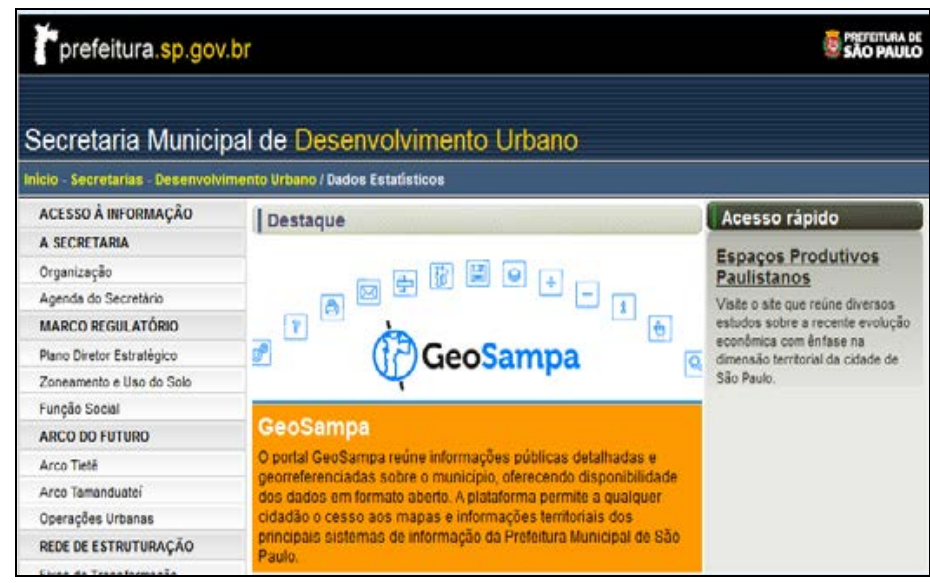

Fonte: Site da Secretaria Municipal de Desenvolvimento Urbano de SP, 2016.

Figura 4 - Mapa de desemprego por faixa etária do município de SP

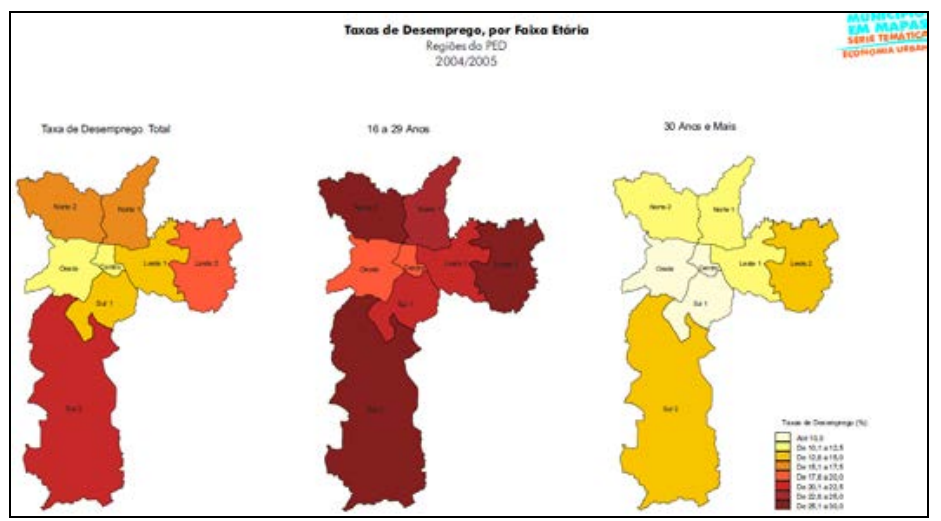

Fonte: Site da Secretaria Municipal de Desenvolvimento Urbano de SP, 2016. 
Sobre o aperfeiçoamento das ferramentas de Sistema de Informações Geográficas (SIG), entende Farina (2006, p. ) que:

[...] O aperfeiçoamento crescente dos SIG e a automação dos procedimentos administrativos permitem estabelecer o processo de urbanização, com instrumentos cada vez mais sofisticados, que facilitam a tomada de decisões sobre operações urbanísticas com um elevado grau de complexidade. Aliado a esse processo de modernização, é preciso, ainda, transcender o planejamento setorial das cidades, que tem impedido a obtenção de uma visão global de suas problemáticas e a formulação de um modelo integrado para seu desenvolvimento futuro $[\ldots]$.

Entretanto, é preciso aliar a construção cadastral às novas tecnologias, dentre as quais os sistemas de informações geográficas. Há muitas opções de softwares, por exemplo: QGIS. O uso de desinformação e de geotecnologias é uma tendência para as administrações municipais, pois, de certa maneira, auxilia o planejamento estratégico dando maior suporte na gestão territorial municipal. A visão espacial e integrada realiza um maior suporte e dá confiança sobre a leitura do território ao gestor e à população. O caso da cartografia em mapa da cidade de São Paulo é um exemplo claro na gestão territorial para delimitar as desigualdades com relação ao desemprego.

$\mathrm{Na}$ gestão municipal, o município de Cuiabá/MT $\mathrm{MT}^{4}$ conseguiu delimitar o fator de renda com relação ao bairro do morador. Isso permite ao gestor verificar qual bairro concentra maior renda, sendo essa uma ferramenta para a gestão dos tributos municipais de território.

4 Município de Cuiabá - MT. Site institucional. Departamento de cartografia. Disponível em: http://www.cuiaba.mt.gov.br. Acesso em 14.07.2016. 
Figura 5 - Mapa de renda do município de Cuiabá - Mato Grosso

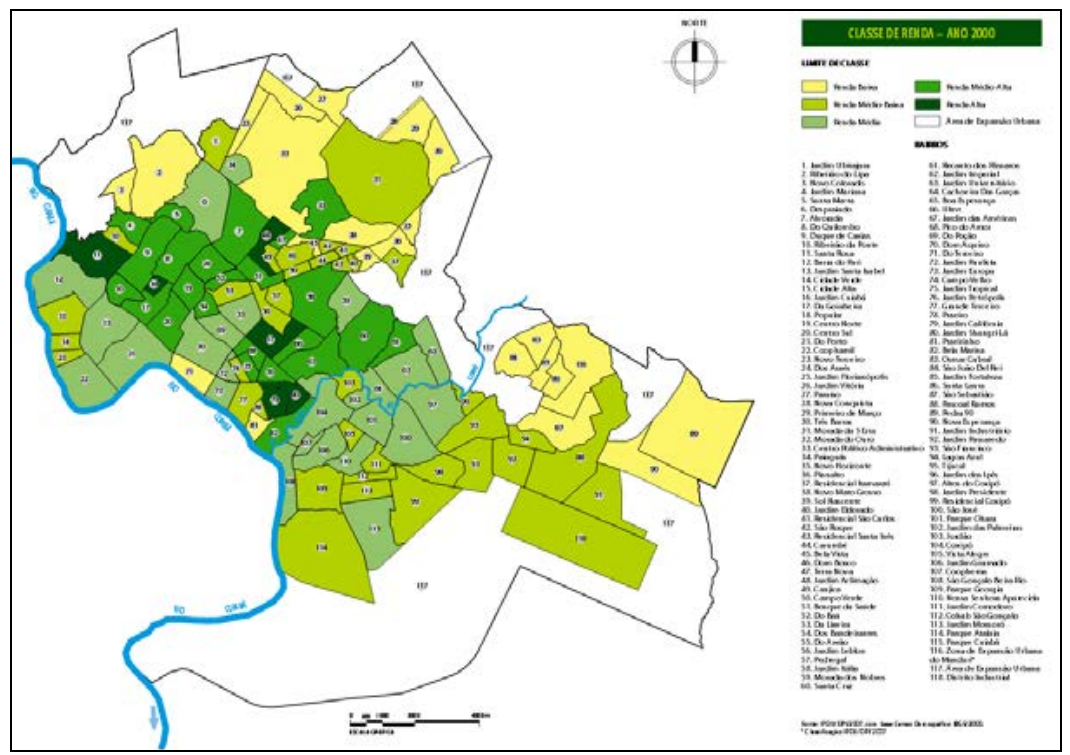

Fonte: Site do Departamento de Cartografia de Cuiabá, 2016.

O gestor público não pode trabalhar somente com o cadastro fiscal; a cartografia temática é uma ferramenta de apoio ao desenvolvimento das cidades. A multidisciplinariedade, para Loch (2004), aliada ao levantamento constante de informações, expressa a necessidade de implantação do Cadastro Técnico, que é instrumento de política fiscal e desenvolvimento urbano e social.

Analisando o mapa de Cuiabá, no aspecto da multidisciplinariedade renda por bairros, aliada ao levantamento constante de informações, pode-se até cogitar uma forma de implantação do Cadastro Técnico Multifinalitário, que é instrumento de política fiscal e desenvolvimento urbano (LOCH, Ministério das Cidades, 2004). Nota-se que o cadastro não necessariamente precisa ser fiscal, são ferramentas de gestão do território, podendo apontar desigualdades ou de maneira temática apresentar a situação em que se encontra o Município. Trata-se de uma leitura e transmissão de informação. 


\section{OBTENÇÃO DE DADOS SOCIOECONÔMICOS DO IBGE}

Os dados de pesquisa do IBGE são de caráter público, porém é comum o usuário ter dificuldades de obtê-lo, principalmente para estudos aos níveis municipais. Pensando nisso, será apresentado um exemplo de extração de dados, em shapefile e tabelas, dos setores censitários do município de Florianópolis - SC, assim como os resultados deles.

Para acesso aos shapefiles do IBGE, é necessário acessar o servidor FTP utilizando qualquer navegador. $O$ link para acesso ao mesmo é: ftp://geoftp.ibge.gov.br/, levando a uma janela semelhante à Figura 5. Como o procurado é referente a dados estatísticos, deve ser selecionado o item "Recorte_para_fins_estatisticos", conforme apontando na Figura 6.

Figura 6 - Aquisição de dados no FTP do IBGE

\begin{tabular}{|c|c|}
\hline प Indice de/ & 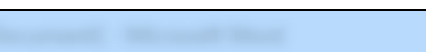 \\
\hline$\leftarrow \rightarrow$ C $\square$ ftp://geoftp.ibge.gov.br & \\
\hline \multicolumn{2}{|l|}{ Índice de / } \\
\hline Nome & Tamanho Data da modificação \\
\hline atlas/ & 09/06/16 18:30:00 \\
\hline cartas e mapas & $02 / 06 / 1604: 35: 00$ \\
\hline imagens do territorio/ & $01 / 06 / 16 \quad 16-52: 00$ \\
\hline informacoes_ambientais/ & $02 / 06 / 1604: 23: 00$ \\
\hline informacoes_sobre_posicionamento_geodesico & 01/06/16 16:58:00 \\
\hline metodos_e_outros_documentos_de_referencia/ & $01 / 06 / 1616-52: 00$ \\
\hline [- modelos_digitais_de_superficie/ & 01/06/16 17:03:00 \\
\hline [1] nomes_geograficos/ & $01 / 06 / 16 \quad 16: 52: 00$ \\
\hline [1] organizacao_do_territorio/ & $02 / 06 / 1604: 30: 00$ \\
\hline produtos_educacionais/ & $02 / 06 / 1619-12: 00$ \\
\hline [- recortes_para_fins_estatisticos/ & $01 / 06 / 1616: 54: 00$ \\
\hline
\end{tabular}

Fonte: Elaborada pelos autores, 2016. 
Dentro dos recortes para fins estatísticos, deve-se procurar a pasta "malha_de_setores_censitarios", conforme Figura 7.

Figura 7 - Aquisição de estatísticos no FTP do IBGE

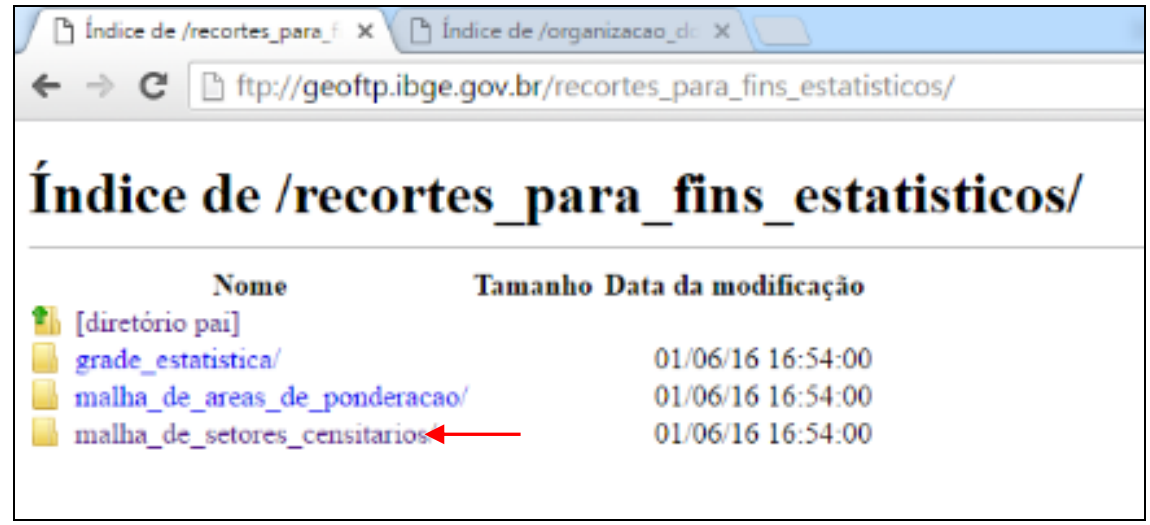

Fonte: Elaborada pelos autores, 2016.

Em seguida, como se pretende trabalhar com os dados mais recentes, deve ser selecionada a pasta "censo_2010", conforme Figura 8.

Figura 8 - Censo 2010

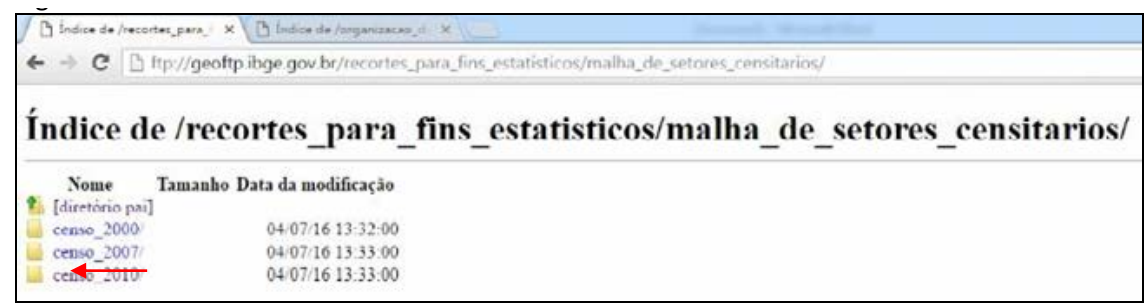

Fonte: Elaborada pelos autores, 2016.

Ao acessar a pasta, será visualizado um arquivo em extensão .txt, o qual deve ser aberto, conforme Figura 9. 
Figura 9 - Censo 2010 Arquivo TXT

\begin{tabular}{|c|}
\hline Índice de/recortes_para_fins_estatisticos/malha_de_setores_censitarios/censo_2010/ \\
\hline 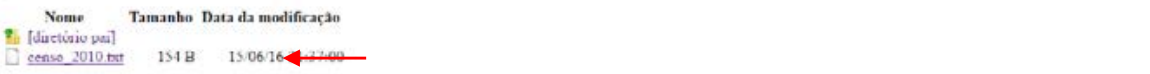 \\
\hline
\end{tabular}

Fonte: Elaborada pelos autores, 2016.

Ao abrir o arquivo, será disponibilizado um link (Figura 10), no qual deve ser copiado e colado, na íntegra, ao navegador.

Figura 10 - Copiando o link

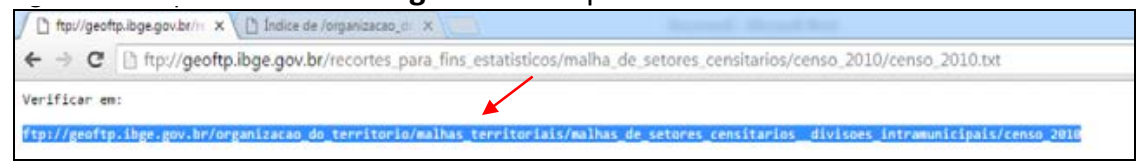

Fonte: Elaborada pelos autores, 2016.

Copiando o link mostrando anteriormente, tem-se acesso a todos os shapefiles de todos os estados do Brasil, como o exemplo se refere a Florianópolis, abrir a pasta "sc" para ter acesso aos dados de Santa Catarina, conforme Figura 11.

Figura 11 - Dados de Santa Catarina

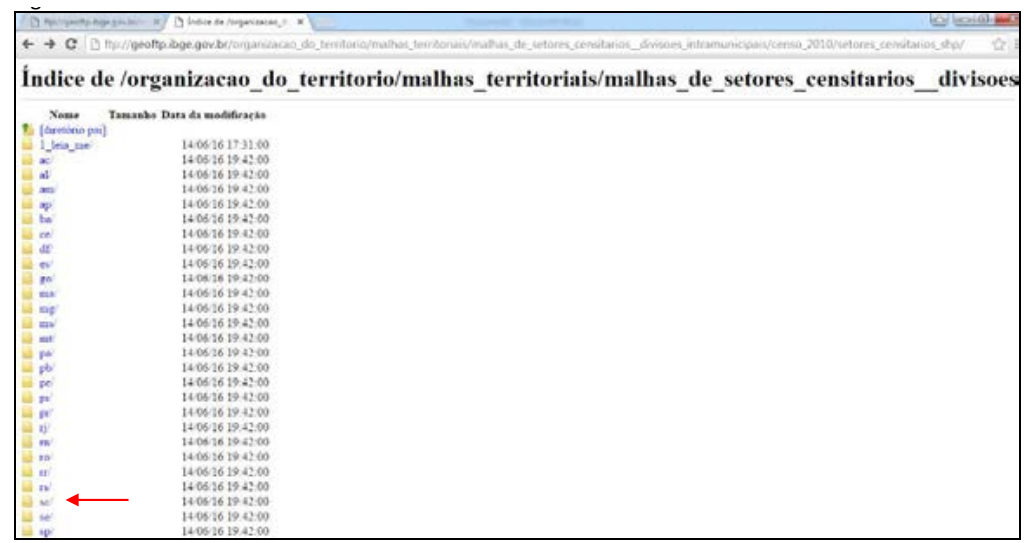

Fonte: Elaborada pelos autores, 2016. 
Ao acessar a pasta do estado escolhido, serão visualizados quatro arquivos. Como a intenção é obter o shapefile no nível de setores censitários, deve-se fazer download do arquivo "sc_setores_censitarios. zip", conforme Figura 12.

Figura 12 - Dados censitários de Santa Catarina

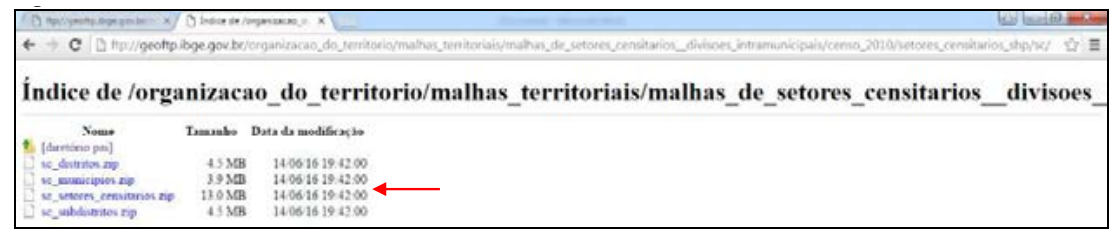

Fonte: Elaborada pelos autores, 2016.

Ao realizar o download, devem-se extrair os arquivos do formato .zip e abrir o arquivo "SC_setores_censitarios" utilizando qualquer programa GIS. Nesse caso, foi utilizado do QGIS para demonstração do shape, conforme visualizado na Figura 13.

Figura 13 - Inserção do shapefile

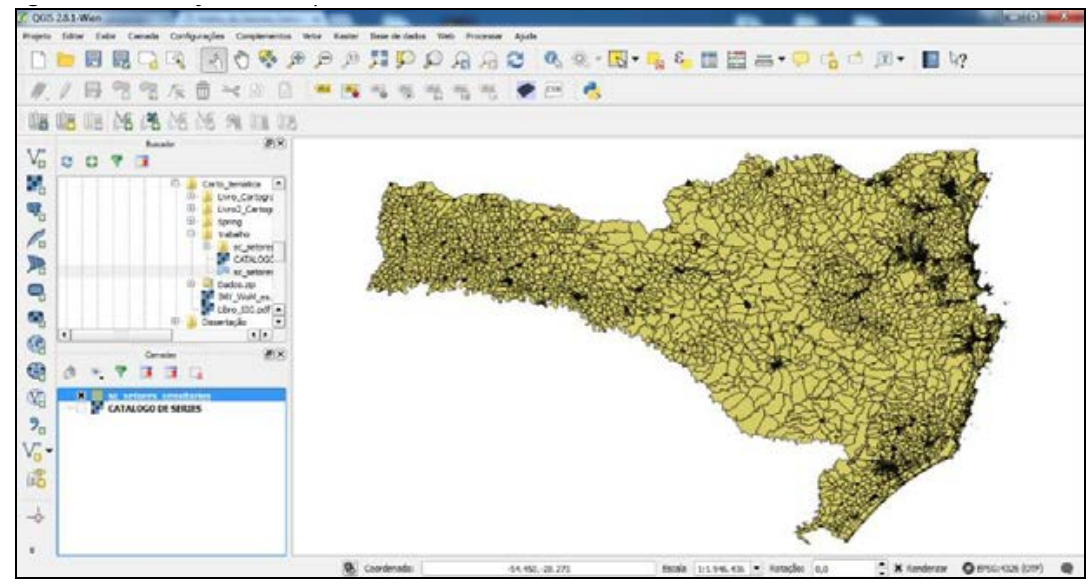

Fonte: Elaborado pelos autores, 2016. 
O procedimento pode ser repetido para qualquer estado e para diferentes shapefiles de acordo com o estudo que será realizado. Na tabela de atributos do shapefile, é possível visualizar um código único para cada setor censitário. É através desse código que será linkada a tabela contendo os dados, como renda, de cada setor censitário.

Para acesso a tabelas do IBGE, é necessário acessar o servidor FTP utilizando qualquer navegador. O link para acesso a ele é: ftp://ftp. ibge.gov.br, levando a uma janela semelhante a Figura 14 e Figura 15. Como o procurado é referente a dados do censo, deve ser selecionado o item "Censo", conforme apontando na Figura 14.

As informações obtidas no órgão são públicas, permitindo a edição das informações, bem como o seu salvamento diretamente na pasta onde se encontram os arquivos. As informações do censo são ferramentas para criação e interpretação dos mapas e dados na gestão territorial.

Figura 14 - Informação Censo

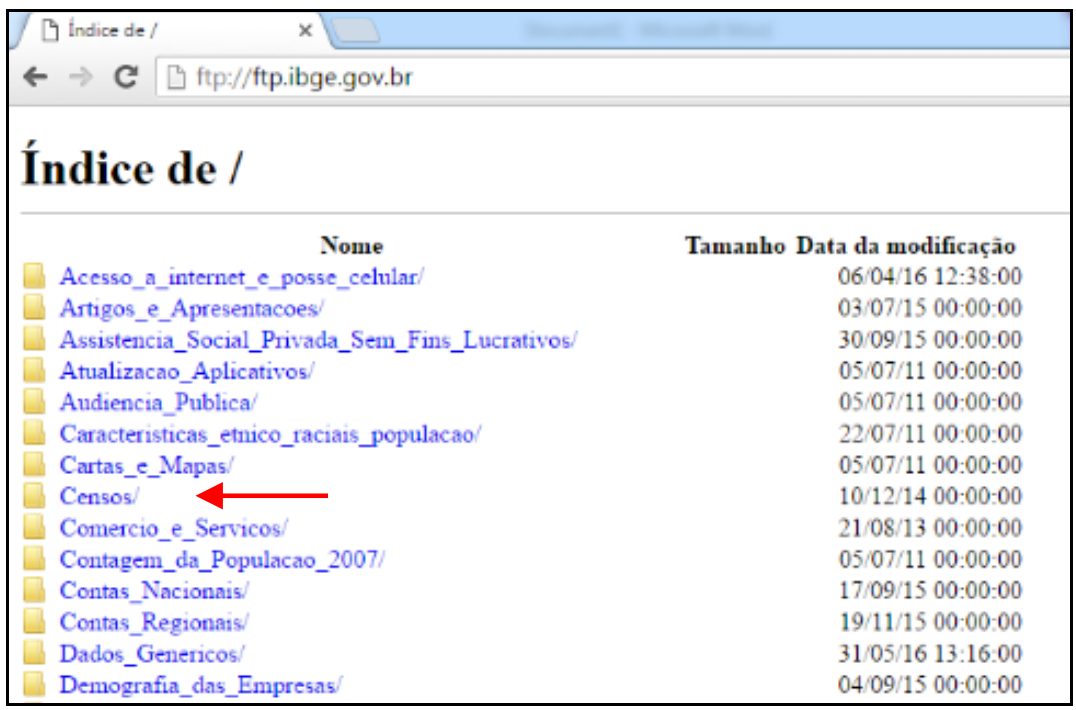

Fonte: Elaborada pelos autores, 2016. 
Figura 15 - Pasta dos dados censitários

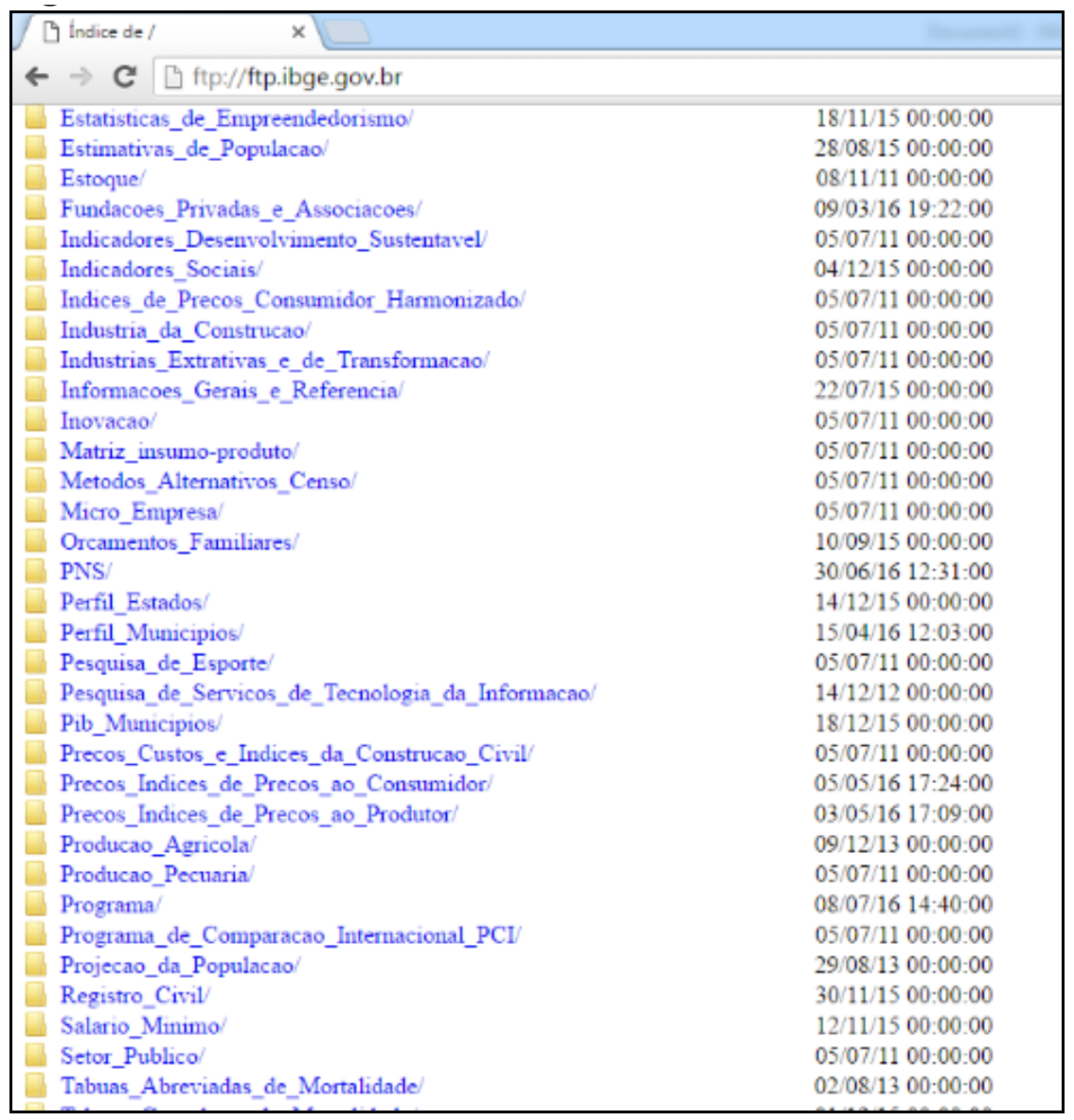

Fonte: Elaborada pelos autores, 2016.

Em seguida, devem-se abrir as pastas, conforme indicado na Figura 3.11, na sequência:

Censo_Demografico_2010" $\rightarrow$ "Resultados_do_ Universo" $\rightarrow$ "Agregados_por_Setores_Censitarios". Em seguida, deve ser realizado o download do arquivo "SC_20150527.zip", que faz referência a tabela de dados de Santa Catarina, conforme indicado na Figura 16. 
Figura 16 - Dados censitários de Santa Catarina

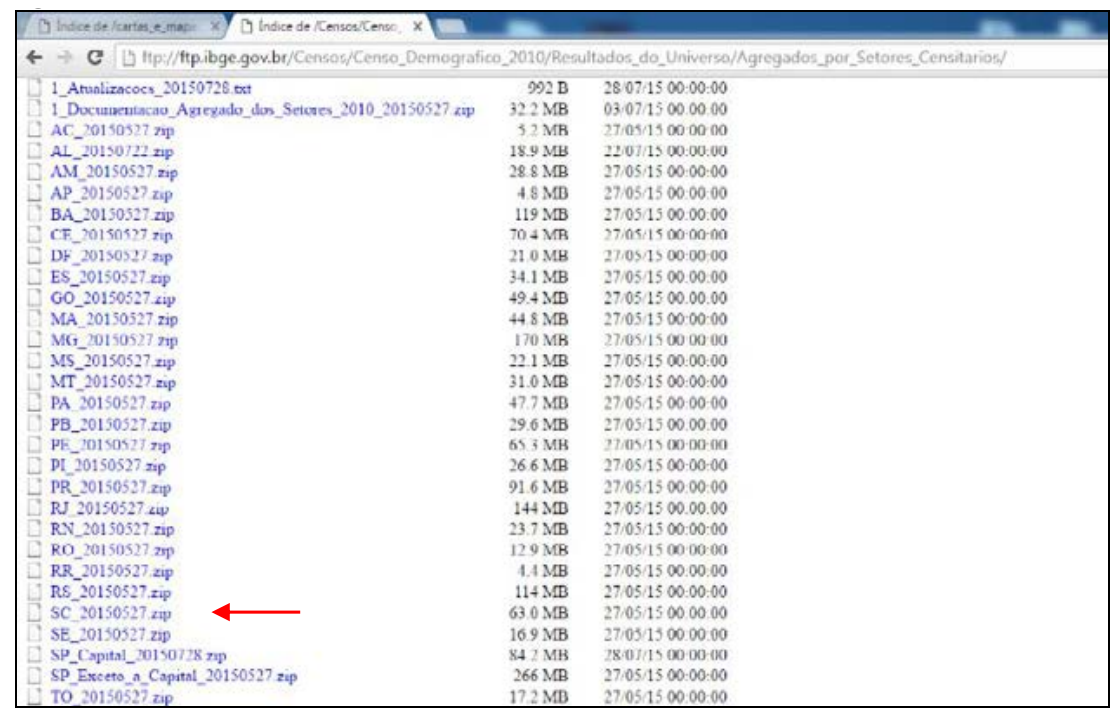

Fonte: Elaborada pelos autores, 2016.

O arquivo "SC_20150527.zip" deve ser extraído para uma pasta. A tabela que contém os dados do dos setores censitário é a "Basico_SC", conforme Figura 17:

Figura 17 - Dados básicos dos censitários de SC

\begin{tabular}{|c|c|c|c|c|}
\hline Name & & Date modified & Type & Size \\
\hline (ख): Bssico_SC & $\longleftarrow$ & $13 / 04 / 201515: 48$ & Microsoft Excel $97 . .$. & $5.011 \mathrm{~KB}$ \\
\hline (1) Domicilic01_SC & & $13 / 04 / 201515: 49$ & Microsoft Excel $97 . .$. & $18.605 \mathrm{~KB}$ \\
\hline Domicilic02_SC & & $13 / 04 / 201515: 49$ & Microsoft Excel $97 \ldots$. & $10.493 \mathrm{~KB}$ \\
\hline DomicilioRenda_SC & & $13 / 04 / 201515: 52$ & Microsoft Excel $97 . .$. & $1.732 \mathrm{~KB}$ \\
\hline ⿶) Entomo01_SC & & $24 / 05 / 201521: 09$ & Microsoft Excel $97 . .$. & $15.620 \mathrm{~KB}$ \\
\hline (ब) Entomo02_SC & & $24 / 05 / 201521: 08$ & Microsoft Excel $97 \ldots$ & $17.049 \mathrm{~KB}$ \\
\hline ⿶: Entomo03_SC & & 24/05/2015 21:08 & Microsoft Excel $97 . .$. & $15.636 \mathrm{~KB}$ \\
\hline ⿶: Entomo04_SC & & 24/05/2015 21:09 & Microsoft Excel $97 \ldots$ & $17.049 \mathrm{~KB}$ \\
\hline ⿶) Entomo05_SC & & $24 / 05 / 201521: 09$ & Microsoft Excel $97 \ldots$ & $17.049 \mathrm{~KB}$ \\
\hline ⿶: Pessoa01_SC & & $13 / 04 / 201515: 58$ & Microsoft Excel 97... & $7.003 \mathrm{~KB}$ \\
\hline (1): Pessoa02_SC & & $13 / 04 / 201515: 58$ & Microsoft Excel $97 . .$. & $13331 \mathrm{~KB}$ \\
\hline बi: Pessoa03_SC & & $13 / 04 / 201515: 59$ & Microsoft Excel $97 . .$. & $19.352 \mathrm{~KB}$ \\
\hline ⿶: Pessoa04_SC & & $13 / 04 / 201515: 59$ & Microsoft Excel 97... & $12.213 \mathrm{~KB}$ \\
\hline Detheres & & 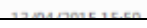 & 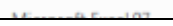 & 1.210 \\
\hline
\end{tabular}

Fonte: Elaborada pelos autores, 2016. 
A tabela pode ser visualizada na Figura 18. Nela, podem ser encontrados diversos tipos de variáveis, além de uma coluna com o código único do setor censitário. Para união dos valores da tabela com o shapefile da área de estudo, deve-se utilizar a função "Join" vinculando os códigos únicos dos setores da tabela com as do shapefile no SIG em que está utilizando. Neste trabalho, não será abordada essa função. A explicação de cada coluna das variáveis se encontra entre os arquivos descarregados do "SC_20150527.zip".

Figura 18 - Dados censitários

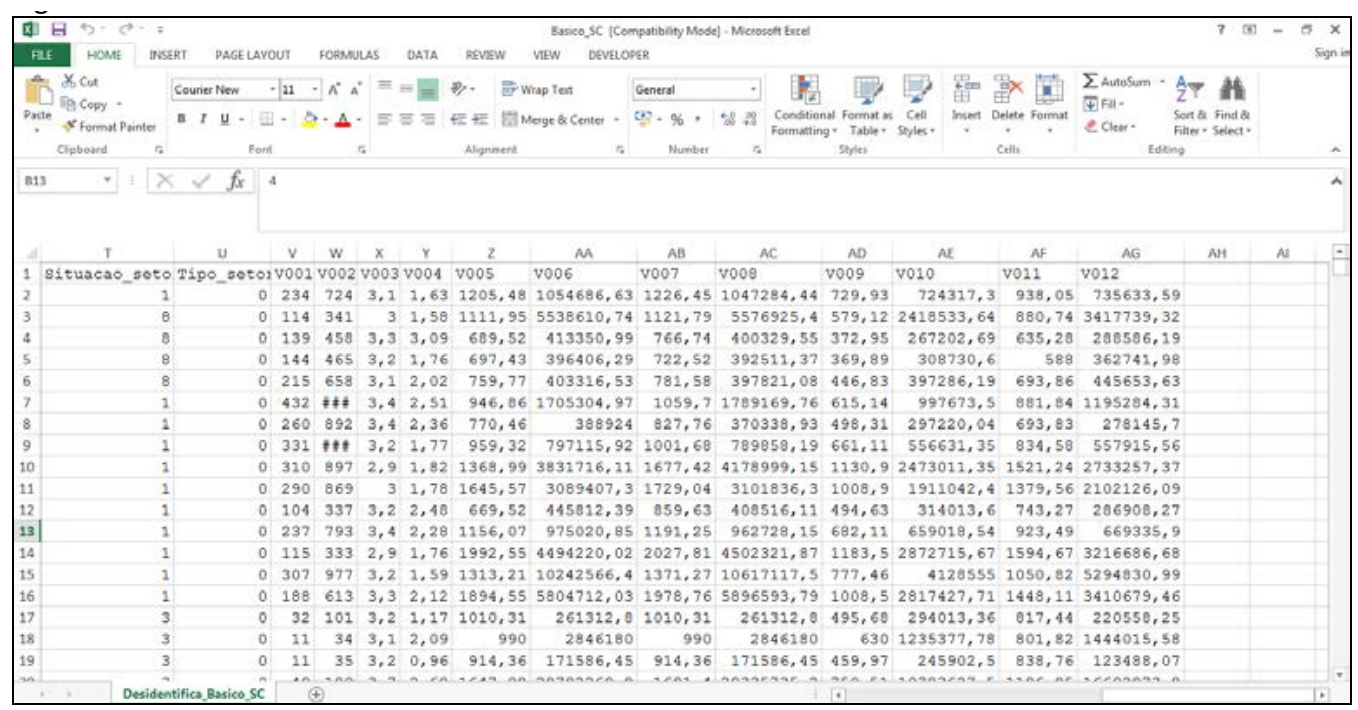

Fonte: Elaborada pelos autores, 2016.

\section{EXEMPLOS DE MAPAS SOCIOECONÔMICOS E SEUS ESTUDOS}

Os mapas socioeconômicos se bem utilizados podem demonstrar as características da área de estudo, assim como podem ser usados 


\section{PLANEJAMENTO E GESTÃO TERRITORIAL}

\section{A Sustentabilidade dos Ecossistemas Urbanos}

como ferramenta de investimentos e previsão do comportamento da área em questão.

O Word Mapper apresenta uma série de mapas envolvendo estudos no mundo, e, entre eles, pode-se destacar o mapa do gasto com saúde de cada país (Figura 19) e o mapa de população mundial (Figura 20), ambos realizados de maneira interessante, apresentando proporção de tamanho de acordo com o quantitativo associado a cada país, contudo é importante que sejam interpretados de maneira cautelosa e em conjunto, pois um país com alto gasto em saúde também pode apresentar grande quantidade de população, não necessariamente sendo altamente desenvolvido na saúde, como seria interpretado intuitivamente sem a apresentação do mapa de população.

Os mapas da cartografia possuem elementos selecionados em um determinado espaço geográfico, utilizando simbologia e projeção cartográfica (DENT 1996). Assim, para os cartógrafos, como já debatido, vale ressaltar que os mapas são veículos de transmissão de conhecimento (NOGUEIRA, 2009), bem como demonstrado nos mapas.

Figura 19 - Mapa de gastos com saúde

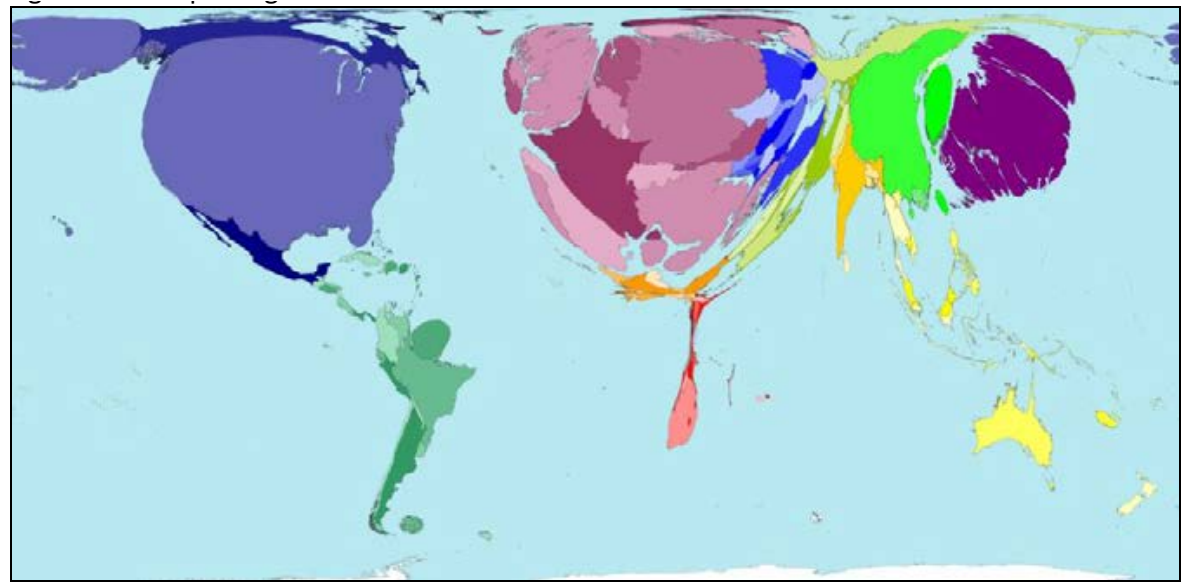

Fonte: http://www.worldmapper.org/images/largepng/213.png, 2016. 
O mapa de gastos com a saúde expressa em uma cartografia de maneira crítica como se tem uma realidade distorcida com os gastos em saúde. Alguns países mostram-se inexpressivos com seus gastos em saúde. Já os mais amplos são os que mais investem no gasto com essa matéria fundamental. O mapa é eficaz, transmitindo de maneira didática e induzindo a crítica os gastos governamentais com saúde.

Figura 20 - Mapa da população mundial

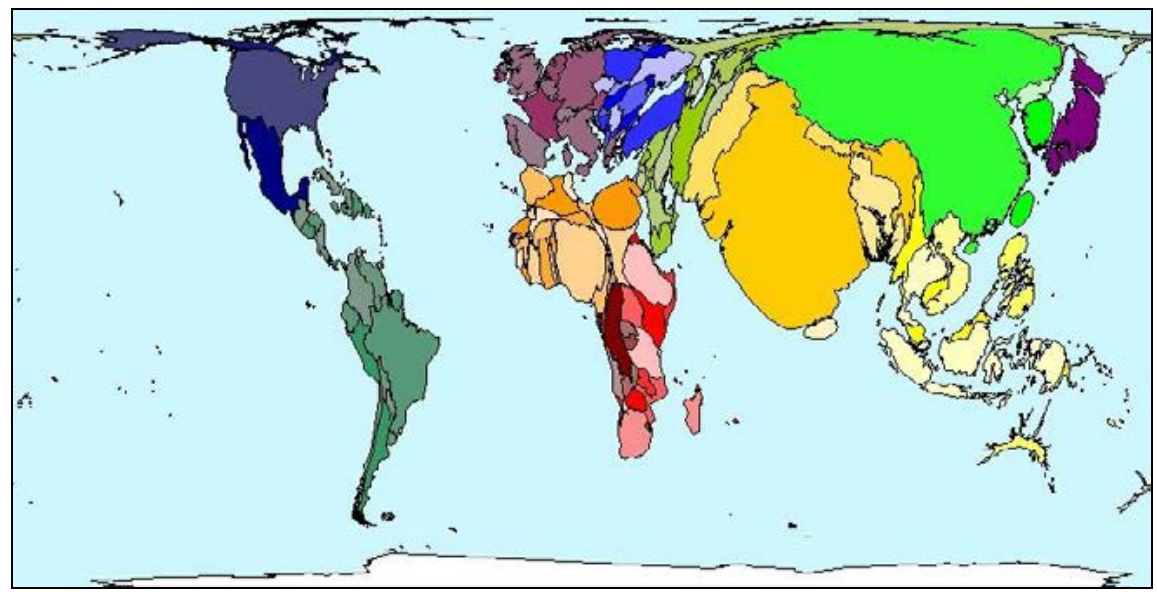

Fonte: http://www.worldmapper.org/imagemaps/imagemap2.html, 2016.

Já a cartografia de população mundial demostra, de maneira ampliada, onde está concentrado o maior número de habitantes da população mundial. A cartografia simboliza e deixa claro o fator de populacional elevado e os riscos sociais decorrentes da crescente demanda por habitação e população.

De outro modo, na cidade de Berlim na gestão local, os mapas são disponibilizados de maneira interativa e on-line, conforme Figura 21, apresentando séries históricas, além de possibilitar a utilização de diversas camadas. Por exemplo, pode-se observar a porcentagem de desempregos dos anos 2011 para 2012, conforme Figura 22. Link para acesso ao sistema: http://fbinter.stadt-berlin.de/fb/index.jsp?Szenario=fbinter_jsc 
Figura 21 - Fonte de dados socioeconômicos da cidade de Berlim

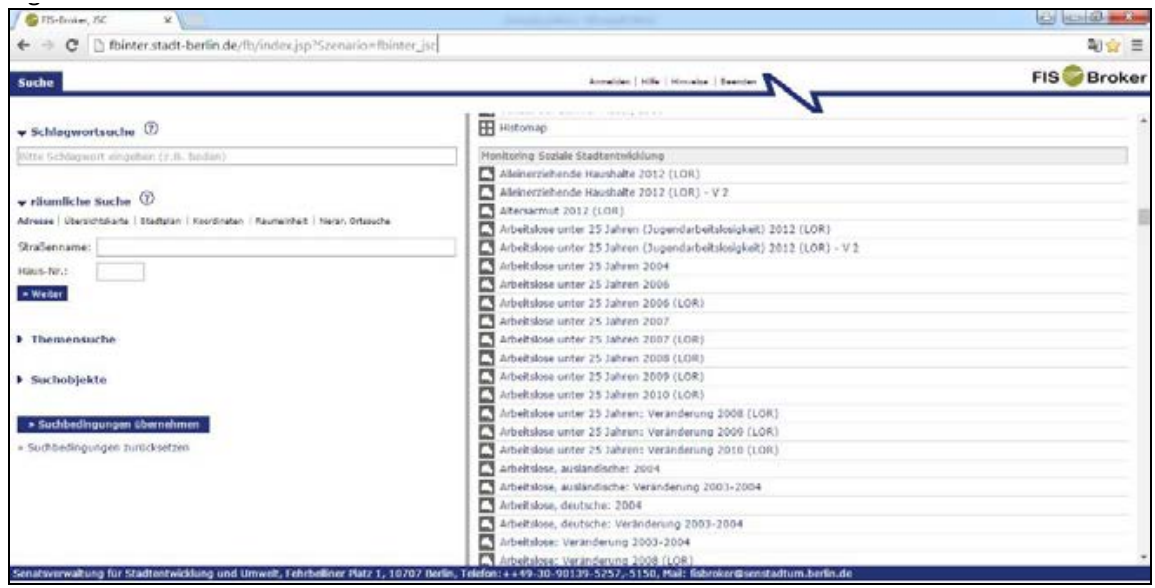

Fonte: http://fbinter.stadt-berlin.de/fb/index.jsp?Szenario=fbinter_jsc, 2016.

Figura 22 - Sistema on-line de dados socioeconômicos da cidade de Berlim

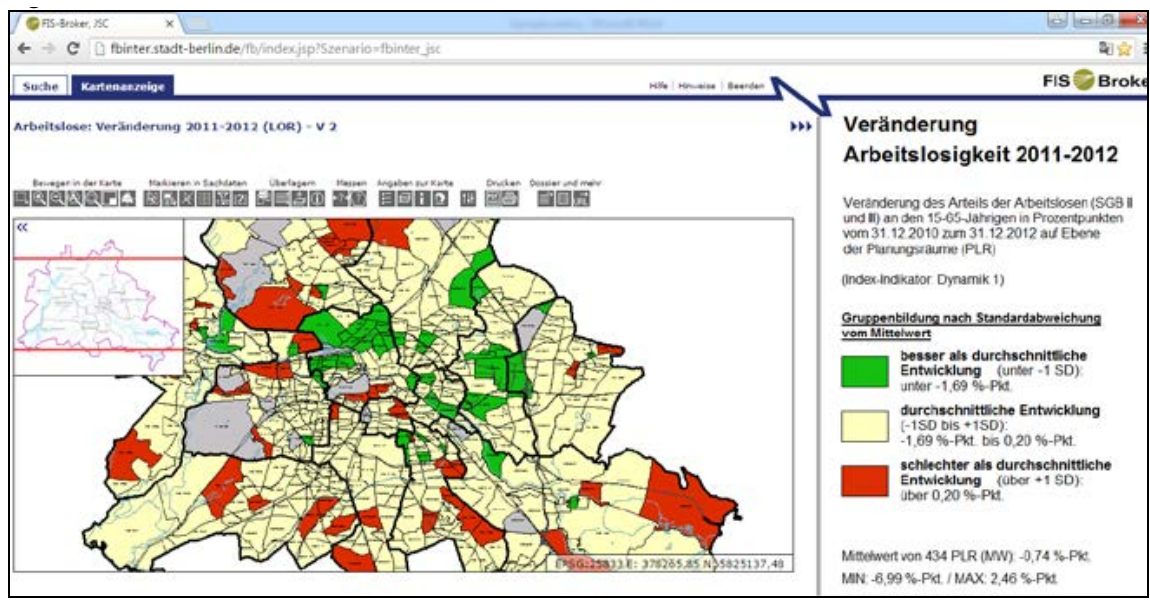

Fonte: http://fbinter.stadt-berlin.de/fb/index.jsp?Szenario=fbinter_jsc, 2016. 


\section{CONSIDERAÇÕES FINAIS}

A gestão do território é um complexo de informações e dados que precisam de debate e interpretação. Os dados socioeconômicos, representados pelas entidades públicas, buscam auxiliar no desenvolvimento da gestão territorial com base em informações, visando à tomada de decisões dentro do espaço territorial.

Entretanto, visando à proteção e desenvolvimento das localidades, cada vez mais se faz necessária a implantação de cadastro, troca de informações e mapeamento de situações. Entender o território é buscar melhorar a condições de governabilidade, enfrentando problemas cotidianos e positivando informações frente aos avanços das novas tecnologias cadastrais e de espacialização de dados e informações.

Logo, os mapas são veículos de transmissão de conhecimento. Essa temática é indispensável como ferramenta de gestão territorial, seja em nível local ou internacional, seja ela com relação à desigualdade, renda, população, questões sociais ou econômicas. É dever de cada gestor buscar fazer uma reflexão crítica do seu território, usando dados disponíveis com base na cartografia e nos mapas.

No Brasil, a função constitucional da União em organizar e manter os serviços oficiais de estatística, geografia, geologia e cartografia de âmbito nacional foi atribuída ao Instituto Brasileiro de Geografia e Estatística (IBGE) - art. 21, XV, o levantamento das informações de geografia e estatística. Entretanto, os estados e municípios podem e devem realizar os levantamentos cadastrais e também trabalhar em forma de cooperação de informações socioeconômicas para o desenvolvimento do território.

Atualmente, encontram-se disponíveis, de maneira pública, os dados censitários para a gestão do território diretamente no site do IBGE, ou ainda, se o desenvolvedor for leigo, pode-se montar o próprio mapa socioeconômico com a ferramenta específica ainda na fase beta, WebCart.

Assim sendo, fazendo uma comparação com outros países, como a cartografia da Alemanha (Figuras 21 e 22), podemos reconhecer 
que há uma evolução na obtenção de dados socioeconômicos na leitura do território e suas desigualdades sociais. A gestão territorial, seja ela federal, estadual e municipal, deve perceber a importância e cada vez melhor aproveitar os dados socioeconômicos e as geotecnologias disponíveis.

A cooperação de informações para o desenvolvimento do território também é de grande importância para o desenvolvimento e crítica nas relações da sociedade atual contemporânea e suas limitações, dificuldades sociais e econômicas.

Os mapas reproduzem a informação e são veículos de transmissão de interpretação e leitura da informação eficazes e disponíveis para a reflexão dessas informações. Sendo assim, com o auxílio das informações socioeconômicas disponibilizadas pelo IBGE, consegue-se fazer uma reflexão dos atuais cenários econômicos e sociais do território.

Dessa forma é de extrema importância a obtenção dos dados socioeconômicos na gestão do território. Integrar os dados e materializá-los é indispensável na atualidade. Cabe ao gestor definir essa reflexão, pois urge a necessidade de aliar as geotecnologias com os dados para interpretação na gestão territorial, seja ela no meio internacional ou nacional, seja ela no meio local.

\section{REFERÊNCIAS}

BARBOSA, Rodolpho P. A questão do método cartográfico. Revista Brasileira de Geografia, Rio de Janeiro, v. 29, n. 4, p. 117-123, out. dez.1967.

BERLIN. SENATSVERWALTUNG FÜR STADTENTWICKLUNG UND WOHNEN. Geoportal Dados cadastrais de Berlin na Alemanha. Disponível em: <http://www.stadtentwicklung.berlin.de/geoinformation/fis-broker/>. Acesso em: 14 jun. 2016. 
BRASIL. Constituição (1988). Constituição da República Federativa do Brasil. Disponível em: <http://www4.planalto.gov.br/legislacao>. Acesso em: 13 ago. 2017

BRASIL. Constituição (1967). Constituição da República Federativa do Brasil. Disponível em: <http://www4.planalto.gov.br/legislacao>. Acesso em: 13 ago. 2017

BRASIL. Decreto lei no 6.666. Institui a INDE. Compartilhamento de dados ano de 2008. Disponível em: <http://www4.planalto.gov.br/legislacao>. Acesso em: 13 ago. 2017.

DENT, B. D. Cartography: Thematic map design. 4. ed. Chicago, USA: Wim. C. Brow Publishers (WCB), 1996.

ESTADO de Santa Catariana. Secretaria de Planejamento Estadual, 2016. Disponível em: < http://www.gespublica.gov.br/content/secretaria-deestado-do-planejamento-sc>. Acesso em: 12 de ago. de 2017.

FARINA. C. FLÁVIA. Abordagem Sobre as Técnicas de Geoprocessamento Aplicadas ao Processamento e Gestão Urbana. FGV. Cadernos do Ebape, v. 4. Disponível em: <www.moodle.ufsc.br>. Acesso em: 10 de ago. de 2017.

INSTITUTO BRASILEIRO DE GEOGRAFIA E ESTATÍSTICA - IBGE. Cidades, 2010. Disponível em: <http://www.ibge.gov.br/webcart>. Acesso em: 14 jul. 2016.

JANNUZZI, Paulo de Martino. Indicadores socioeconômicos na gestão pública. Florianópolis: Departamento de Ciências da Administração/ UFSC; Brasília: CAPES: UAB, 2009. 
LOCH, C.; ERBA, D. A.Cadastro Técnico Multifinálitário Rural e Urbano. Cleveland: Lincoln Institut of Land Policy, 2007.

LOCH, Carlos: Cadastro Técnico Multifinalitário: instrumento de política fiscal e urbana. In: Curso de Cadastro Técnico Multifinalitário. Brasília DF: Ministério das Cidades, 2004.

SECRETARIA MUNICIPAL DE DESENVOLVIMENTO URBANO DE SÃO PAULO; Município em mapas. Série Temática. Economia Urbana. São Paulo - SP. Disponível para pesquisa no site institucional da Prefeitura. Disponível em: <http://www.prefeitura.sp.gov.br/cidade/secretarias/desenvolvimento_ urbano/dados_estatisticos/>. Acesso em: 14 jun. 2017.

MARTINELLI, MARCELO. Um breve apanhado sobre a breve história da cartografia temática. Anais. $3^{\circ}$ Simpósio iberoamericano de história da cartografia. São Paulo, 2010.

NOGUEIRA. E. Ruth. Cartografia. Representação, comunicação e visualização de dados espaciais. 3. ed. Florianópolis: Ed. UFSC, 2009.

OLIVEIRA, Cêurio de. Curso de cartografia moderna. Rio de Janeiro: IBGE, 1993. Disponível em: <https://servicodados.ibge.gov.br/Download/ Download.ashx?http=1\&u=biblioteca.ibge.gov.br/visualizacao/livros/ liv81158.pdf>. Acesso em: 1 jan. 2016.

PEDROLLO. Jandira Maria. Perfil socioeconômico de Cuiabá (Org. Adriana Bussiki Santos; coordenação Cuiabá, MT: Central de Texto, 2010. v. 4. Disponível em: <http://www.cuiaba.mt.gov.br/upload/arquivo/perfil_ socioeconomico_de_cuiaba_Vol_IV.pdf>. Acesso em: 14 jun. 2016. 
SANCHEZ, Miguel C. Conteúdo e eficácia da imagem gráfica. Boletim de Geografia Teorética, Rio Claro, v. 11, n. 21-22, p. 74-81,1981.

SECRETARIA Municipal de Desenvolvimento Urbano de São Paulo. Disponível em: <http://www.prefeitura.sp.gov.br/cidade/secretarias/ urbanismo/dados_estatisticos/>. Acesso em: 14 jun. 2016.

SEPLAN - Secretaria do Planejamento, Mobilidade e Desenvolvimento Regional do Estado do Rio Grande do Sul. Disponível em: <http:// planejamento.rs.gov.br/inicial>. Acesso em: 18 jun. 2016.

TRATA BRASIL. Disponível em: <http://www.tratabrasil.org.br/fontes-dedados>. Acesso em: 13 jun. 2016.

WORLDMAPPER. Collection of world maps. Mapas elementos de figura 19 e 20. Disponíveis em: <http://www.worldmapper.org/>. Acesso em: 12 jun. 2016. 